\section{Joel Lazar}

is president of the McLaughlin

Lazar Group, and is

responsible for all timeshare/

fractional consulting and sales

and marketing management

operations. Joel has spent

more than 15 years in both the

timeshare and fractional areas

of the resort business. He has

held senior management and

executive positions with the

Owners Club, Intrawest

Resort Ownership Corp.,

Cimarron Golf Resort and

Hilton Grand Vacations Co.

Joel serves on the American

Resort Development

Association's board of

directors and as chairman of

the ARDA Membership

Development Committee.

Wallace Hobson CRE

is a partner with Hobson

Ferrarini Associates, providing

real estate economics

consulting from Portland,

Oregon.

\section{Keywords:}

fractionals, timeshare, whole ownership, vacation, affluent, Telluride
Joel Lazar

President

McLaughlin Lazar Group, Inc.

7380 Sand Lake Rd., Suite 500

Orlando, FL 32819

USA

Tel: +1 4073521008

Fax: +1 4073520998

E-mail: JLazar@MLGroupinc.com

Website: www.MLGroupinc.com

Wallace Hobson

Consultant

Hobson Ferrarini Associates

610 SW Alder Street, Suite 515

Portland, OR 97205

USA

Tel: +15032266616

E-mail:wmh@hobsonferrarini.com

\section{Papers}

\section{Private residence clubs: A new concept for second home ownership}

\author{
Joel Lazar and Wallace Hobson
}

Received (in revised form): 12 February 2002

\begin{abstract}
The resort industry is entering a period of explosive growth, and luxury fractional second homes, also called private residence clubs (PRCs), are the latest craze in the continued evolution of the resort industry. The market is currently untapped and is demonstrating pent-up demand. The PRC appeals to affluent vacation homebuyers who are reluctant to invest a substantial amount of capital in a second or third home that receives infrequent use. A PRC offers a viable alternative to whole ownership for these buyers. This paper describes fractional resort products in their current evolutionary cycle. Included are the key features of a luxury fractional home that set it apart from traditional timeshare and fractionals positioned in the low or moderate tiers of the market. The concept and function of a PRC, the product features that meet the needs of a sophisticated discerning consumer and emerging trends in the industry are addressed in this paper.
\end{abstract}

\section{INTRODUCTION}

Understanding the difference between a traditional timeshare $(1 / 51$ share) and a fractional (one-quarter to $1 / 21$ shares) is important to absorb properly this discussion of fractionals and private residence clubs (PRCs). From a literal standpoint the terms 'timeshare' and 'fractional' are interchangeable. From a legal standpoint they are treated the same by all states currently regulating timeshare. The differences between the two have evolved from developers' need to distinguish their fractional offerings promotionally from the typical timeshare product. In addition to share size, differentiators include higher product cost, higher price points and lower marketing cost. While timeshare projects usually target households with minimum incomes of US $\$ 50,000$, fractionals are targeting minimum incomes of US $\$ 150,000$. The fractional product is further segmented with the PRC combining all the benefits of fractional ownership and many of the amenities and services of a five-star hotel and targeted at the most affluent consumers. 


\section{Evolving market}

\section{Geographical expansion}

\section{Private residence clubs}

\section{PRODUCT CONCEPT}

Historically, the one-quarter fractional is a time-tested product that has sold successfully to unrelated parties. However, based on design, finishes, services, project amenities, management and price, this product has traditionally been positioned to target the lower and middle-range of the second home market. High disposable income is associated with more leisure time and a preference for luxurious surroundings. In the case of affluent households with minimal leisure time the promotional emphasis is placed on the well-documented psychological and spiritual need for family vacations.

In response to a desire for a high quality alternative to a wholly owned second home, without the cost and responsibilities, sales of fractional interests of luxury condominiums, townhouses and single family cottages/homes are demonstrating there is a market with strong untapped demand. In 1999, the 35 projects known to exist in North America with active sales programmes had a total sales volume of approximately $\$ 190 \mathrm{~m}$. In 2000 , the 42 active projects had a volume of about $\$ 470 \mathrm{~m}$, representing about a 150 per cent increase. $^{1}$

Although the vast majority of the recently completed fractional projects are located in the Rocky Mountain ski areas, the concept is spreading rapidly to other popular resort destinations in the USA, the Caribbean and Mexico. In addition to ski resorts, these destinations include golf resorts and beach resorts.

The coupling of the concept of a private club with shared ownership is a recent trend that adds sophistication and a higher level of exclusivity to the product. Included are a private clubhouse and five star hotel services that are not available with wholly owned resort real estate. The club functions like a private golf club where the members are entertained with social events and form social relationships with other members.

The PRC is marketed as a real estate investment, not vacation time. The emphasis is on 'relationship selling' rather than 'mass merchandising'. It is a soft sell approach and repeat visits prior to closing are the norm. The target market may have a negative impression of timeshare and will not respond to high-pressure sales tactics or sales gimmicks.

The PRC concept strives to create exclusivity and a sense of belonging, and caters to the sophisticated wealthy buyer at the top of the social strata. The competition is wholly owned vacation real estate, not timeshare. Condominium rental pools and lock-off rooms (which enable timeshare owners to utilise their units as two separate and functional units) are inappropriate and will detract from exclusivity. In fact, any access available to the general public will detract from the exclusivity. Owners or members are willing to pay a premium for the added security and social advantages afforded by a PRC. The PRC owner/member profile type prefers small, controlled and upscale environments in which they can meet and socialise with like-minded affluent guests. 


\section{Unit configuration}

Price is secondary motivation

\section{Discerning buyers}

\section{PRODUCT CHARACTERISTICS}

The high-end fractional is in the earliest stage of the product life cycle. The majority of residence clubs are in the planning stages or rumoured. Several are under construction and a relatively small number have been completed. Thus, the industry is in its most rapid stage of evolution, with new players and development structures emerging. Market knowledge and consumer familiarity and acceptance of the concept will also evolve as a greater number and variety of product types, at varying price ranges, are introduced.

In general, three-bedroom units are the most common fractional unit type, followed by two bedrooms. While the unit mix varies somewhat by location, three bedrooms typically account for one-half to two-thirds of all units, while two bedrooms comprise roughly onethird of the supply. However, four-bedroom homes are gaining in popularity. One-bedroom units are not recommended as they have languished in the few projects with these in their mix. The market is expressing a preference for larger units, particularly in the more elite resort locations. This follows the logic of buyer motivation being an alternative to second home ownership. A second home will generally provide two or more bedrooms and allow greater flexibility as to use. The fractional and PRC buyer prefers to retain that flexibility. Typical sizes range from 1,800 to 2,000 square feet for two bedrooms and 2,200 to 2,600 square feet for three bedrooms.

Given that a luxury fractional home competes against whole ownership, the buyer is more focused on the size, quality and use structure of the programme than the price, which becomes secondary considering a cost per share at 20-25 per cent of whole ownership for comparable size and quality. Thus, assuming an additional expense of $\$ 25,000$ to $\$ 50,000$ for three bedrooms instead of two bedrooms, price is relatively inelastic given the income bracket and net worth of the typical buyer.

Project density should be appropriate for the area, but will mostly be driven by zoning and land cost, coupled with the characteristics of the market that will purchase the product. In some markets multistorey condominiums may be appropriate, while other locations and sites could be developed as single-family homes or cabins. Virtually any housing product can potentially be fractionalised as long as the quality of the design and location is appropriate for the higher end of the market with respect to PRCs. Attention to the details of the design, finishes, furnishings, landscaping and amenities is critical. Buyers are discerning and expect the best.

A members-only clubhouse is an important component of the amenity package and facilitates social interaction among the club owners. The clubhouse, at a minimum, should include a lobby with a check-in desk, management offices, a private lounge and dining area, workout facilities, a spa, massage rooms, and a pool with a spacious sun deck. Additional services, like a personal trainer, massage therapist and pre-arrival grocery shopping, should be made available on a contract basis. 
Origin of PRCs

Warmer climates

Accessible resorts preferred

\section{LOCATION AND ACCESS}

High-end fractional condominiums and PRCs began in the Rocky Mountain ski areas of Telluride and Deer Valley. The Franz Klammer Lodge in Telluride, Colorado and the Deer Valley Club in Deer Valley, Utah were the earliest entries into the market. The concept rapidly spread to other national ski areas including Snowmass/Aspen, Steamboat Springs, Sun Valley, Park City, Vail, Jackson Hole and Lake Tahoe. Telluride, in particular, has been a magnet for residence club development and may, as a consequence, be overbuilt.

Although fractional resorts were initially established in the Rocky Mountain ski areas, the concept has begun to expand rapidly to warmer climates with beaches and golf, such as Mexico, the Caribbean, Florida, Arizona and northern and southern California.

Conditions for luxury fractionals require locations that are already popular resort areas with the affluent market, preferably national and international destinations. Fractionals work best in markets where the cost of wholly owned second home real estate is out of reach for most households, and in markets that are experiencing rapid price escalation. It is important to have some combination of a strong base of scenic natural amenities, an ideal climate, pristine beaches, skiing, golf courses or other attractions that draw substantial numbers of vacationers.

Resorts accessible from a large market by both automobile and airplane may have a competitive advantage over more isolated resorts dependent on air transportation. For example, the golf resorts in North and South Carolina receive excellent patronage from households travelling by both modes of transportation, as does Lake Tahoe, which is located within four hours' drive time of 4.5 million households. Conversely, many of the Rocky Mountain ski areas are too far from major population centres to be accessible by automobile for the majority of their patronage.

The principal advantage of close proximity to major markets is that the owners are able to use the facility more frequently for shorter stays, with less transportation cost and more flexibility on arrival and departure times.

The importance of access cannot be overemphasised. Whether travelling by automobile or airplane, consumers will tolerate four to five hours of time to reach a favourite destination, perhaps more by air. However, markets where access is more than six to eight hours become secondary markets, unless these locations are unique and cannot be duplicated in more accessible locations. Since 11 September this dynamic has been magnified, with projects closer to feeder markets benefiting from not only a quicker recovery but perhaps a long-term shift in vacationers' travel profiles.

\section{USE AND OWNERSHIP}

Shares of a residence club are typically sold in fractions ranging from one-seventh to $1 / 12$. The average in Rocky Mountain ski areas 
Fractional sizes

Seasonality

Ownership

Registration is one-seventh. Beyond these limits the project takes on the appearance of timeshare. Buyers are more sensitive to the perception of exclusivity and amount of use they will receive than the price. They are already paying substantially less than a wholly owned vacation home The quality and construction cost often result in individual units valued at well over $\$ 1 \mathrm{~m}$. These clubs are the four-and five-star products in the industry.

The size of the fractional interval is based upon the guaranteed delivery of prime time to the buyer. Thus, the length and characteristics of high, low and shoulder seasons is the determinant of the fractional size. In the ski areas, with less demand in the autumn and spring, the fractional size is less. For example, with a one-seventh fraction, two weeks in the prime seasons of summer and winter can be guaranteed, a total of 28 weeks per unit. The balance of 24 weeks in the shoulder seasons is utilised on a space available reservation system. This period is called float time.

In a warmer climate with a longer high season, like Hawaii, a smaller fraction can be used. For example, a one-tenth share, with four weeks guaranteed, results in 40 weeks of guaranteed use and 12 weeks of float time. The float time occurs during the three least popular months. Hotel occupancy patterns, average daily rate (ADR) and revenue per available room (rev PAR) are the best gauge of seasonal variations. Other sources are tourism visitation data.

Occupancy of fractionals in ski areas is typically high in the winter ( 95 per cent) and averages 75 per cent in the summer. Warmer climates like the Caribbean, Mexico and Hawaii will experience higher year-round use, usually in a range of $80-85$ per cent occupancy.

Fractional ownership is usually evidenced by a deed representing an undivided deeded interest (UDI), equal to the size of the fractional share purchased, in a specific unit. Buyers stay either in the same unit in which they have legal ownership each time they visit, or in any like unit of the type they purchased. Most PRCs do not guarantee a specific unit to maximise flexibility in the reservation process.

Fractional registration in most states is the same process as timeshare. Promises for resale services or rentals at the point of sale cannot legally be made without potentially violating state and federal securities laws. Legal issues in foreign countries like Mexico and some Caribbean destinations can be complex, and must be thoroughly researched before proceeding.

\section{PRICING}

Since most resort markets have few, if any, fractional projects to guide pricing value, appraising in the absence of comparable sales has been problematic. The accepted methodology is to establish a wholly owned pricing structure for the residence club based on the price per square foot of comparable condominiums, attached 
townhouses, and single family homes. A 1.5 to 2.0 multiplier is then added to these prices and divided by the number of shares to obtain the pricing for a fractional share. (Table 1)

The multiplier selected is both market and cost driven and is justified based on several factors.

- A residence club is more expensive to construct. The multiplier covers the added cost of land, a clubhouse, furnishings and appliances for the home and the clubhouse, superior finishes and higher marketing costs compared with wholly owned properties.

- There are additional interest carrying costs from a potentially longer absorption period due to the number of individual sales.

- A PRC has the advantage of five star services, not available with most wholly owned vacation properties.

- The multiplier can reflect other competitive factors, including a five-star hospitality brand, high barriers to entry that limit competition and a premium for a master-planned destination resort.

- There is an inverse relationship between fraction size and the multiplier, with a lower multiplier for larger fractions.

- Because the price is substantially less than whole ownership, in total dollars, a higher price per square foot can be charged for a product with less price elasticity.

The price range for a share in a PRC is highly variable depending on the location, quality and fraction size of the product. Generally, prices range from approximately $\$ 125,000$ to over $\$ 400,000$, with square foot prices ranging from $\$ 500$ to $\$ 2,000$.

In addition to the purchase price, annual maintenance fees are

\section{Other fees} charged, similar to homeowner association fees in wholly owned condominiums. These fees typically range from $\$ 4,000$ to $\$ 9,000$ per year. There are also daily housekeeping fees.

\section{MARKETING AND SALES}

Fractional products have much lower sales costs than timeshare due to a reliance on intercept and relationship marketing as opposed to mass marketing. The number of shares and closings is only seven to 12 per unit, compared with as many as 50 for a timeshare. However, marketing costs are still significantly higher than wholly owned vacation real estate, and generally average approximately $15-20$ per cent. 


\section{Sales and marketing}

Small developers
Although these marketing cost percentages are lower than timeshare, which can average as much as $40-50$ per cent of sales, the total sales dollars spent are still relatively substantial because of the higher unit values. The advantage of fractionals over timeshare is that more of the buyer's dollar goes towards 'bricks and mortar'. Therefore, the potential for appreciation (or at least value retention) rather than depreciation is greater. Value appreciation is important since the consumer expects property appreciation from wholly owned second homes.

With respect to end-user financing, experience shows that approximately 40 per cent of buyers will finance their fractional purchase. The balance are cash buyers. Typically, as the price per share increases, the number of cash buyers will also increase. While it is prudent to have an end-user financing programme, the buyers are well connected and usually have their own preferred sources of financing.

\section{DEVELOPMENT COMMUNITY}

The evolution of the fractional development industry can be divided into three stages with respect to the types of developers delivering the product to the market.

- The smaller individual entrepreneur.

- The established developers of major master planned resorts.

- The large development and brand name hospitality companies who develop and operate resorts nationally and internationally.

\section{First- and second-stage entrepreneurs}

In the current early stages of development in the fractional resort industry, the majority of the developers have been relatively small individual entrepreneurs. In many cases the stage one developer has limited real estate experience. The development process and operations are trial and error. These developers were the first to build stand-alone PRCs.

Second-stage developers are also independent entrepreneurs, but they typically have more real estate experience and are often better capitalised.

The individual entrepreneur is still active and will continue to play an important role in the fractional industry. However, they must have a good location and the ability effectively to execute the development and ongoing operations of the PRC, and will continue to see competitive pressure from branded entries.

\section{The master-planned resort}

Many of the fractional products developed to date are free standing facilities. There is a growing trend to offer fractionals as a component of a planned resort community. While master-planned resort communities are longtime fixtures in resort development, the introduction of the upscale fractional into the planned community is new. 


\section{Mixed use}

\section{Successful integration}

\section{Brands}

\section{Market depth}

Currently, large integrated resort development companies are formulating plans to add PRCs to their product mix in their respective resort locations. These fractional projects will be integrated into the resort with the wholly owned products, the hotels and timeshare. Five-star hotels and PRCs are particularly complementary and efficient uses since the hotel operator can also manage the PRC. All users and owners share a common resort amenity base that often includes retail, dining facilities, golf courses, a ski mountain, a spa and fitness club and other amenities. The PRC will have exclusive clubhouse facilities in addition to the common resort amenities.

The master developer of the resort may build the fractional or spin the land to a specialised developer. The more exclusive the resort, the greater the opportunity for a high-end fractional.

One of the potential problems with the master planned resort approach is that homeowners may complain if any type of timeshare, fractional or rental condominiums are constructed. They must be convinced the PRC will not detract from the image of the resort. The use of separate private gated communities within the master-planned resort may help circumvent these concerns. The exclusive nature of the PRC must be communicated to the homeowners, who are also candidates for membership. The owners clubs at Barton Creek, Homestead and Hilton Head are all components of master-planned communities into which they have successfully integrated their fractional PRC product.

\section{Large developers and brand-name hospitality companies}

Ritz-Carlton, Four Seasons, Rosewood, Club Corp of America, Carlson Hospitality Worldwide through Regent International and Club Regent and others have begun developing or formulating partnerships to develop residence clubs.

The Ritz-Carlton hotel chain has an active fractional programme with at least two projects under construction and several others planned. Carlson/Regent is under construction with their first project. Four Seasons is currently planning several projects.

\section{SOURCES OF DEMAND AND BUYER PROFILE}

A confluence of demographic and economic trends has created a growing market for second home and resort development. The resort industry is forecast to be the fastest growing real estate market over the next 20 years, fuelled by demographic shifts, wealth creation and inheritance. Baby-boomers are entering peak earning years and are purchasing second homes at an increasing rate. Approximately 13 per cent of home sales were second home purchases in 1999, compared with 8 per cent in $1995 .^{2}$ Of these second home buyers, 38 per cent paid cash.

The buyer profile of resort fractionals is typically high-echelon professionals, corporate executives and entrepreneurs whose most precious asset is time. When on vacation they want a high level of 


\section{Buyer profile}

High income

Baby boomers luxury and service and usually stay in four- or five-star resort hotels, or an expensive vacation condominium or single-family home in their favourite resort destination. They are frequent repeat visitors to the area.

Many high-paying secondary jobs have been created by rapid economic expansion in professional fields like law, accounting, advertising and graphics, mortgage banking and other types of service industries. Silicon Valley in northern California and the high-tech industry in Seattle have been the primary driving force in some resort markets like Hawaii.

Households utilising expensive rental properties are not, however, the only targets. Owners of second homes are also prospects. Having experienced the frustrations of a wholly owned vacation home, they may be ready to trade into a fractional where maintenance, vandalism and theft are not an issue. They receive, in turn, at least equal luxury plus the addition of a clubhouse, services and social interaction with their peers. These second homeowners often do not have the time to use their home more than five or six weeks a year. They can trade into a fractional and have capital left to invest. Second homeowners may also be looking for a third home in a different area from their second home.

Timeshare owners are another source of potential buyers if they have the income and motivation to trade up into a residence club. They have tried timeshare and may be looking for an alternative to a wholly owned second home.

Income and net worth is high for PRC buyers. Typically annual incomes start at $\$ 250,000$ and often range from $\$ 500,000$ to over $\$ 1,000,000$ and more. A minimum income threshold is $\$ 250,000$ per year for a fractional share that is priced at $\$ 200,000$.

Although income is the best indication of the ability to purchase, it is conservative with respect to measuring the depth of the market. Many households whose incomes may disqualify them as viable buyers, have enough wealth to purchase a fractional share. The parents of baby boomers are the wealthiest generation in history. A substantial amount of wealth in the baby boomer generation has been created through inheritance, and this trend will be exacerbated in the future as the baby-boom population ages.

Another source of wealth is the unprecedented increase in primary home equity throughout the USA. The recent change in the tax code that allows up to $\$ 500,000$ of gain without taxes every three years has increased the propensity for more households to own a second home, particularly among new empty nesters. These households can sell their large family home, move down to a less expensive home, and have money left over to invest in a second home. A fractional product offers many advantages to these households, particularly for households who are not retired and have limited leisure time.

Understanding the typical buyer profile of a fractional residence club drives the product concept, design and marketing. The 
following summarises the key characteristics and motivations of the typical fractional buyer.

- The luxury fractional buyer can afford a wholly owned vacation home, but may have difficulty justifying the investment due to infrequent use. However, they want more use and schedule flexibility than they receive with timeshare.

- The fractional buyer wants extensive amenities and hotel services that are usually not available with wholly owned homes. They want a high level of service and amenities, and are willing to pay the associated costs.

- The fractional buyer is a repeat visitor to the resort area in which the property is located, often visiting more than once per year.

- The fractional buyer will not respond to high-pressure sales tactics or sales gimmicks. Two to four visits to the property are common before a sale is made.

- The target audience may have a negative impression of timeshare. Differentiating the product and sales approach from timeshare and communicating to the buyers who are purchasing a second home is critical.

- It is essential for the management and sales staff to understand they are selling real estate, not vacation time.

- The marketing and sales process is shorter then general real estate and more protracted then traditional timeshare.

- Proper due diligence (feasibility study) during the earliest part of the conceptual stage is critical to the success of a fractional project. This highly specialised work product should be produced by a fractional specialist. Alternatively, a hotel feasibility firm partnering with a specialist can suffice in some cases.

\section{EMERGING TRENDS}

The previous sections of this paper depict how the high-end resort fractional industry has evolved to its current state. Although the new fractional concept is still in its infancy, it is important to understand the trends that are likely to shape the future as the industry matures and moves into new stages of the product life cycle. Increased competition will force developers to do a better job of managing the development and marketing process and providing consumers with product and service refinements that create more value.

\section{Market entry of the major development and branded hospitality companies}

One of the most important emerging trends is the market positioning taking place in the fractional industry by major national and international hospitality companies. As previously discussed, Ritz-Carlton, Four Seasons, Rosewood, Club Regent and others have begun developing or branding PRCs. 


\section{Role of the majors}

These major hospitality clubs will have important competitive advantages over independent developers and even large singlelocation resort developers.

- First, branding in the resort industry, whether it is timeshare, hotels or other resort products, is a major international trend. The brand names are trusted and bring sophisticated operations experience and certainty to the development process from the perspective of the buyer. The creditability associated with the name, particularly with the five-star hotels like Ritz Four Seasons and Ritz Carlton, creates a competitive advantage in selling to the affluent target market. These companies have a proven ability to deliver promised five-star services and amenities.

- Second, the hospitality companies have lists of prospective buyers through their hotel and timeshare operations. They can offer attractive marketing programmes and incentives to visit a PRC, including a free stay at their nearby four- or five-star hotel. The five-star hotel company is able to sell to a qualified audience that trusts and is loyal to their brand. Marketing costs can be significantly reduced.

- Third, these companies have extensive financial and personnel resources and contacts. They are able to obtain debt and equity financing quickly.

- Fourth, the marketing arm of these major hospitality companies is long and effective. They have the advantage of a broad following and can more efficiently use major advertising expenditures by jointly advertising all of their resort products together.

- Fifth, combining a five-star hotel with a residence club is efficient. It spreads the cost of amenities, like a golf course, over a larger base and increases the operating revenue to the hotel disproportionate to any increase in operating expenses. Revenue from the sale of real estate can be used to reduce the debt on the hotel.

- Finally, fractional branding by a four- or five-star hospitality company will command a price premium in the market and accelerate absorption. Thus, there is substantial economic value in the right brand. Diligence is required in the brand negotiating process. Particular attention should be afforded to marketing access to the brand's affinity base and determining if the target profile matches the profile of that group.

Although the market entry of the hospitality companies creates competitive threats to the smaller independent developer, it also creates opportunities in the form of franchising and joint ventures between private entrepreneurs and the hospitality companies. Four Seasons, Rosewood, and Club Regent are all joint venturing the majority of their projects with independent developers. 
Consumer awareness

Fractional exchange systems
Thus, the entry of the major hospitality companies is likely to have a profound impact on the future of the industry. While some smaller developers maybe squeezed out of the market, others will form close associations and prosper. However, the major benefit is going to be increased awareness and acceptance in the marketplace due to the greater advertising exposure of the fractional product by the hospitality companies. At this period in the evolution of the fractional segment it is too early to declare a 'one off' or a 'branded chain' superior to the other.

\section{Mixed-use destination resorts}

Certainly the growing popularity of large, mixed-use, masterplanned resorts will enhance the quality and market exposure of the PRC. The PRC is a natural addition to the product mix of large destination resorts. It can successfully co-exist with wholly owned condominiums and townhouses, timeshare, hotels and single-family detached homes, all of which appeal to a somewhat different market. The residence club provides more housing units to absorb the high cost of amenities and infrastructure, and it will accelerate sales and revenue since the product does not compete directly with the other resort housing.

\section{Formation of specialised marketing companies}

Another emerging industry business model is the former independent fractional developer who develops a niche by specialising as a marketing and sales company that sells their development knowledge and skills to other developers with less experience. This marketing and sales service does not necessarily preclude these companies from continuing to develop their own projects as well, although conflicts could occur if they develop within the same markets as the clients to whom they are selling their services.

\section{Exchanges}

Although exchanges are well established in the timeshare industry, they are only in the beginning stages among high-end fractionals. Traditional timeshare exchange companies such as Resorts Condominium International and Interval International are attempting to enter this market. However, to be successful the product must be carefully segmented from timeshare, to the point of setting up a separate entity with a different name. Blending timeshare exchanges with residence club exchanges will detract from the exclusivity of the club and may turn buyers away. While independent exchange services may offer the promise of a potential service that can enhance the residence club, it must be within a relatively small family of comparably priced fractional products.

Exchanges are, however, likely to become more important in the future, as the larger companies building PRCs assemble a number of projects in various locations. Internal exchanges within the same 


\section{Value retention}

\section{Appreciation}

organisation may be more acceptable to the market than an independent exchange service. A five star hotel company can even offer fractional owners exchanges into hotels throughout the world.

\section{Fractional resale and appreciation}

The resale value of the fractional market has yet to be established. However, because marketing costs are significantly lower than timeshare, and because the concept has taken on an aura of exclusivity, the opportunity for investment appreciation or, at a minimum, value retention appears excellent.

Some industry experts say resale appreciation will be the primary determinate of the future success and continued strong demand for fractionals. The buyers have the capacity to purchase a wholly owned second home and the experience in the wholly owned vacation market raises expectation for value appreciation.

The authors believe the cost of the fractional share is not the primary purchase motivator and that the expectation for appreciation is secondary compared with the quality, availability, amenities, and services offered. The outcome of these viewpoints will evolve over time as more fractional shares are offered in the secondary market. It is likely that some projects will experience appreciation on resale, while others may not.

However, as long as the pricing of fractionals is within reason in relation to wholly owned second home products, there should be appreciation in areas where the wholly owned recreation real estate is increasing in value. The rate of appreciation may not necessarily be the same. It could be more because the product is more affordable, with respect to the total purchase price for comparable quality and a larger income qualified market.

The one example of a project of sufficient age to provide a history of resales over several years is the Deer Valley Club in Park City, Utah. The annual turnover rate has been 5 per cent and the average annual rate of appreciation of fractional interests has been 16 per cent. If this example is indicative of normal appreciation, the future of fractionals is assured.

\section{Urban fractionals}

A further evolution of the fractional concept is the addition to the market of the urban fractional. To date the only urban PRC completed and in sales is the Phillips Club at the Lincoln Center on Manhattan Island in New York City. Sales are strong and the developers, Millennium Partners, are planning similar clubs in other major metropolitan areas.

There are two markets for urban fractionals. The first market is the urban vacationer who enjoys the setting of a place like New York with the restaurants, cultural opportunities, shopping, and other activities unique and different from resorts.

The second market is the affluent business traveller who spends significant amounts of time in these cities. The club ambience, the 
Urban growth

\section{Boutique hotels}

\section{Overbuilding}

\section{Financing}

services and the special treatment, coupled with ownership, is an attraction over a five-star hotel. The small and intimate ambience of an exclusive club is appealing compared with a 200 - or 300 -room high-rise hotel, or even a boutique hotel. In addition, the Phillips Club is experiencing strong demand for rentals as a long-term extended-stay hotel.

There are many cities across the USA and overseas that are excellent candidates for urban fractionals. Boston, Washington DC, San Francisco, London, Paris, Rome, Hong Kong, Singapore and other major cities that are the business centres of the world, and that also attract affluent tourists, are all candidates for urban fractionals. This concept offers great promise and can be sold at a high multiple.

\section{Other trends}

A way to create a fractional product quickly, at perhaps a lower cost, is through the conversion of boutique hotels and wholly owned condominiums, or enhancement and renovation of a quality timeshare. This form of development is likely to be particularly prevalent for urban fractionals. Although there are not any current examples, conversions will most likely occur in the future and, depending upon the character of the building, could appeal to the high end of the market. This opportunity is particularly appropriate for some countries in Europe where development restrictions can preclude new construction.

As fractionals increase in popularity, different product tiers and therefore different price points will emerge. The popularity of fractionals has been established in the high end of the market. This will attract the less affluent portion of the market, who want what they currently cannot have. Thus, fractionals will emerge at lower price points.

One of the time-tested dilemmas of real estate is the cyclical overbuilding of markets. Fractionals are not immune from these cycles, and if too many projects are constructed in a single resort location, absorption will slow and price reductions may be necessary to liquidate excess inventory. Thus, there are limits to the number of fractionals that can be built in any single resort area. The cream is skimmed off the market, and pent-up demand evaporates.

The difficulty of obtaining both debt and equity financing for fractionals has been holding the new supply in check and limiting overbuilding. The financing process is long and arduous for individual entrepreneurs without the credit lines of the major resort and hospitality companies. Presales are a condition of funding.

Today the profit margins for fractional development are generally very high. It can, however, also be argued that the risk is also proportionately higher than wholly owned real estate because the developer has to make seven to ten times the number of sales. It is not uncommon for an immature product type to come on to the 


\section{Profit margins}

\section{Explosive growth}

\section{Whole ownership alternative}

\section{Absorption}

market with high prices and great cash flow potential. The increased competition from the major hospitality companies is likely to create pricing and profit pressure on the independent developers who do not have the advantage of a major brand name.

There may currently be a price umbrella in the industry that reduces barriers to entry and invites more competition. As competition increases, the relationship between supply and demand changes. Sales may slow, so developers will reduce prices to increase absorption, thus lowering margins. In the future lower prices and profit margins are likely. Lower prices, however, will have the benefit of expanding the market.

\section{SUMMARY AND CONCLUSIONS}

The resort industry is entering a period of explosive growth, and luxury fractional resort products are becoming a significant and recognised component of this industry. Over the last two to three years, new fractionals have, with a few exceptions, been very successful, generating an increased level of interest in the product. To date poor performance in the market has been the result of bad design or marketing execution, an inappropriate location or use structure, or overbuilding in the case of Telluride, Colorado where the Franz Klammer, River Club and Owners Club have all suffered financially.

Luxury fractional products target an affluent market, and must be differentiated from timeshare. The typical buyer of these units can afford a wholly owned vacation home, but may have trouble justifying the investment in light of limited use. These buyers expect high levels of amenities, and are willing to pay for these services.

Marketing to fractional consumers is best done with 'relationship selling', as the fractional buyer will not typically respond to highpressure sales tactics. These consumers are often repeat visitors to an area.

Fractional units are typically sold in fractions ranging from oneseventh to $1 / 12$ interests. Buyers are sensitive to the perception of exclusivity and the amount of use. The number of fractional intervals offered is a function of the amount of prime time that can be guaranteed and the length of the season in the area in which the fractional is located.

The pricing of fractional units typically relies upon a 1.5 to 2.0 multiplier over its market value as a wholly owned housing unit. The multiplier reflects market risk and higher construction costs, as well as the value of the amenity package and the availability of fivestar services. Annual maintenance fees are also charged, similar to a homeowners' association fee in a wholly owned condominium project. Typical marketing costs are in the range of 15-20 per cent of total revenue.

Absorption rates at fractional developments are fairly consistent, with projects typically reporting eight to 12 shares sold per month, averaging approximately ten shares per month. A higher level of 
Potential demand

Brand versus independent

Future variability was reported by projects in ski resort areas, which may reflect a greater diversity of product offerings and, in some cases, overbuilding and market saturation.

The depth of the market and demand, particularly pent-up demand, appears to be significant and stronger than one might anticipate given the high income requirements for ownership. Newly created wealth has broadened the market beyond what household income statistics would indicate. The continuing decline in equity markets may dull demand in the short term. On the other hand, the downturn in the stock market and the economy may induce some second home buyers to seek the more fiscally conservative alternative to wholly second home ownership offered by fractionals.

The early innovators in the industry have been entrepreneurs, with major hospitality companies now making investments in the industry. The hospitality companies will have competitive advantages $v i s$ - $a$-vis independent developers, bringing brand credibility, exposure to prospects, greater resources and marketing skills. On the other hand, the major hospitality companies may not have the flexibility and rapid decision-making capabilities of the smaller entrepreneur.

While rapidly gaining recognition, the industry in its current permutation is still relatively immature. As a result, opportunities for development and innovation are prevalent, with achievable yields compelling. Over a longer period of time, independent developers will need to establish a niche to coexist successfully with the hospitality companies and national resort developers. These include franchising, partnering and the formation of specialised marketing companies.

\section{References}

1. RCI Consulting survey, August 2001.

2. ARDA survey of recreational property owners, Acxiom/DataQuick and USA Today. 